\title{
A INVALIDADE DA REPUTAÇÃO ILIBADA E DA IDONEIDADE MORAL: REFLEXÕES DECOLONIAIS
}

\section{Estevão Rafael Fernandes ${ }^{1}$ \\ Igor Veloso Ribeiro ${ }^{2}$}

\section{Resumo}

O objetivo deste artigo é discorrer sobre vivências não performatizadas dentro da cis-heteronormatividade eurocêntrica hegemônica face à ausência de representatividades queer/transviadas em relevantes funções públicas no país, particularmente no Judiciário. Para o acesso a diversos cargos do Poder Judiciário e outras carreiras jurídicas, além de notório saber jurídico, é exigido pela norma constitucional brasileira, dentre outros requisitos, "reputação ilibada" e/ou "idoneidade moral" por parte do candidato - conceitos fluidos, de grande abstração, mas usados e entendidos pelo senso-comum (moral social/positivada) como pertencentes àquela pessoa enquadrada em padrões morais normatizados. Entendemos esta moral social como fruto de um processo colonial, refletindo processos de colonialidade, dado que a noção de "moral e bons costumes" reforça estereótipos de gênero, família, corporalidade, comportamento e moralidade normalizados conforme valores modernos (e, portanto, euronorcentrados, binários e cristãos). Perspectivas decoloniais permitem um exercício de reflexão crítica sobre a constituição e consolidação tanto das noções de reputação ilibada como a idoneidade moral. Ao final, demonstramos que a "reputação ilibada" e "idoneidade moral", como dispositivos morais constitucionais são esvaziados ao serem lidos em conformidade com os princípios liberais subjacentes de Direitos Humanos.

Palavras-chave: Reputação ilibada. Idoneidade moral. Interdisciplinarieade. Decolonialidade. Direitos humanos.

\footnotetext{
${ }^{1}$ Doutor em Ciências Sociais pela Universidade de Brasília. Professor do Departamento de Ciências Sociais da Universidade Federal de Rondônia, do Programa de Mestrado Profissional Interdisciplinar em Direitos Humanos e Desenvolvimento da Justiça pela Universidade Federal de Rondônia e colaborador no Programa de Pós-Graduação em Antropologia da Universidade Federal do Mato Grosso. E-mail: estevaofernandes@gmail.com

${ }^{2}$ Mestrando no Programa de Mestrado Profissional Interdisciplinar em Direitos Humanos e Desenvolvimento da Justiça pela Universidade Federal de Rondônia (PPG/DHJUS). Cursando Master in Business Administrationem Parcerias Público-Privadas e Concessões na Fundação Escola de Sociologia e Política de São Paulo (FESPSP). E-mail: igorvelosor@gmail.com
} 


\section{INTRODUÇÃO}

Este artigo discorre sobre vivências não performadas dentro da cis-heteronormatividade eurocêntrica hegemônica em face da ausência de representatividade queer/transviada ${ }^{3}$ (não heteronormada) nas mais relevantes funções públicas da República. A constatação deste fato torna-se particularmente relevante, para efeitos de análise e reflexão, dada a diversidade da conformação social brasileira. Com efeito, para o acesso a diversos cargos do Poder Judiciário e outras carreiras jurídicas, além de notório saber jurídico, é exigida pela norma constitucional brasileira, dentre outros requisitos, que o candidato possua "reputação ilibada" e/ou "idoneidade moral", conceitos fluidos, de grande abstração, mas usados e entendidos pelo senso-comum (moral social/positivada) como pertencentes àquela pessoa adequada à moral e aos bons costumes.

Entendemos que essa moral social é parte de relações de colonialidade (cf. Lugones, 2014), na medida em que constitui continuidade de relações de discursivas tributárias da ideia de cis-heteronormatividade euronorcêntrica hegemônica desde os tempos da colonização - neste sentido, "colonialidade" implica um conjunto de relações de poder mantidas mesmo após o processo de independência política, sobretudo no tocante a questões relativas à raça, gênero e classes sociais. Indo de encontro a essa perspectiva, uma visão decolonial e desde uma perspectiva da moral construtivista tanto a reputação ilibada como a idoneidade moral traduz afronta aos princípios liberais subjacentes aos Direitos Humanos, que na perspectiva de Carlos Santiago Nino, em sua obra Ética e Direitos Humanos, são os princípios: a) da autonomia pessoal; b) princípio da inviolabilidade da pessoa e; c) princípio da dignidade da pessoa humana, pois a escolha através de uma moral positivada do perfil de profissional adequado para as carreiras jurídicas favorece alguns e exclui e nega a própria humanidade de muitos outros dissidentes, causando uma grande frustração de perspectivas de planos de vidas e fortalecendo estereótipos, engessando as superestruturas jurídicas.

\footnotetext{
${ }^{3}$ Segundo Miskolci (2012, p. 32) o termo "Teoria Queer" surgiu nos Estados Unidos, em idos de 1991, como um rótulo que buscava encontrar o que há de convergente em um conjunto "disperso ou relativamente disperso de pesquisas". Os estudos queer são a perspectiva teórica e política que passa a se relacionar com os ultrajes que historicamente atuaram como dispositivos discursivos que silenciaram, envergonharam e atemorizaram os gays, as lésbicas e as pessoas transgêneros. Berenice Bento (2017, p. 250) ensina que tais estudos giraram em torno dos seguintes eixos: a) desnaturalização das bioidentidades; b) ênfase nas relações de poder para interpretar as estruturas subjetivas e objetivas da vida social; c) permanente problematização das binariedades; d) prioridade à dimensão humana; e) crítica ao binarismo de gênero ( masculino vs. feminino) e afetivo (homoafetividade vs. heteroafetividade). Ocorre que para os estadunidenses o termo queer é inteligível, mas não faz nenhum sentido no contexto brasileiro. Numa perspectiva decolonial, Bento adotou o termo "estudos transviados"; para ela ser um transviado no Brasil poder ser "uma bicha louca", "um viado", "um travesti", "um traveco", "um sapatão". Neste artigo usaremos o termo transviados ao nos referirmos às minorias sexuais (gays, lésbicas, biafetivos, trangêneros, transexuais, travestis, não-binários, intersexuais, pansexuais, assexuais, two spirit; e mais...), objetivando tanto a ressignificação como a contraposição à cisheteronormatividade eurocêntrica hegemônica. Com efeito, para o léxico, a palavra transviado pode ser entendida como o que ou aquele que obedece os padrões comportamentais vigentes (cf. HOUAISS), buscamos a ressonância dessa palavra pois tem o condão de abarcar todo o cabedal de condutas dissidentes, que, por sua vez, clamam por representatividade.
} 
Diante de tais premissas, abordamos o problema da invalidade de uma norma moral positivada extremamente arraigada em entes supraindividuais numa sociedade liberal, o que se faz por meio de pesquisa de abordagem qualitativa, com revisão bibliográfica e, também, descritiva. Tal discussão sobre poder, Estado, nação, liberalismo e sexualidades não-normatizadas não é nova: mais recentemente, por exemplo, o termo "homonacionalismo" traduz a incorporação, por Estados liberais, da retórica da diversidade, como contraponto a ideias trazidas por imigrantes muçulmanos.

Ao final, demonstramos que a "reputação ilibada" e "idoneidade moral", como dispositivos morais constitucionais, são esvaziados ao serem lidos em conformidade com os princípios liberais subjacentes de Direitos Humanos. Sendo, portanto, moralmente e juridicamente inválidos.

\section{A REPUTAÇÃO ILIBADA E A IDONEIDADE MORAL COMO NORMA MORAL POSITIVADA E A PERSPECTIVA DECOLONIAL}

A Constituição da República Federativa do Brasil, alcunhada de Constituição-cidadã reiteradas vezes, a exigência de preenchimento dos requisitos de "reputação ilibada" e "idoneidade moral", cumulativa ou conjugadamente, somados a outros tantos requisitos específicos para o acesso a diversos cargos e funções públicas ${ }^{5}$, especialmente para aqueles destinados ao quinto constitucional e à chefia de órgãos, porque com investidura precedente de nomeação seletiva de competência do Chefe do Poder Executivo.

O Supremo Tribunal Federal, guardião da Constituição, compõe-se de onze Ministros, escolhidos dentre cidadãos com mais de trinta e cinco e menos de sessenta e cinco anos de idade, de notável saber jurídico e reputação ilibada. Os Ministros do STF são nomeados pelo Presidente da República, depois de aprovada a

\footnotetext{
${ }^{4}$ Paulo Bonavides (2004, p. 372) já alertava que o antagonismo de interesses entre elite social brasileira, vinculadas a lideranças reacionárias, programam a destruição do Estado social brasileiro. Ensina que "se isto acontecer será a perda de mais de cinquenta anos de esforços constitucionais para mitigar o quadro de injustiça provocado por uma desigualdade social que assombra o mundo e humilha a consciência desta Nação. Mas não acontecerá, se o Estado social for a própria Sociedade brasileira concentrada num pensamento de união e apoio a valores igualitários e humanistas que legitimam a presente Constituição do Brasil".

${ }^{5}$ É sedimentado que agente público é toda pessoa física que atua como órgão estatal, produzindo ou manifestando a vontade do Estado. Por sua vez, há diversas classificações e subclassificações para agentes públicos, a expressão em si tem utilidade limitada, porque indica a condição de órgão do Estado submetido a um regime jurídico genérico. As classificações se dão, usualmente, conforme o tipo de vínculo com o Estado, a natureza das funções exercidas, o modo na qual se deu a investidura, os direitos e deveres compromissados e assim por diante. É interessante perceber que na doutrina há a classificação entre agentes políticos e não políticos. Os agentes políticos, no sentido mais próprio, são aqueles representantes da vontade do povo investidos através de mandatos eletivos. Já os agentes não políticos têm a natureza de suas atribuições mais estreitamente relacionadas com a aplicação do direito e ao fomento à satisfação dos direitos fundamentais. Para Marçal Justen Filho (2005, p. 571) os exercentes de funções jurisdicionais, do Ministério Público ou Tribunal de Contas, são agentes não políticos, mesmo que seus regimes jurídicos constitucionais os assegurem contra interferências e restrições, o que se traduz em imunidades e privilégios somente reconhecidos aos agentes políticos.
} 
escolha pela maioria absoluta do Senado Federal ${ }^{6}$. A leitura primeira que fazemos é que a notoriedade do saber jurídico e a reputação ilibada dos integrantes do STF são condições sem a qual o acesso aos cargos é intransponível. Este dispositivo em particular tem uma força normativa fortíssima quando consideramos que o paradigma de Corte Maior se espraia e informa todas as outras cortes patrícias. A mensagem, então, é que para ser integrante do Poder Judiciário é mister gozar na exata medida dessas duas exigências.

A conjugação desses requisitos são exigidas também para a composição do Superior Tribunal de Justiça $^{7}$; do Superior Tribunal do Trabalho ${ }^{8}$; para o exercício do cargo de Advogado-Geral da União\%; para membros do Ministério Público e advogados que pretendem acessar um quinto dos lugares dos Tribunais Regionais Federais, dos Tribunais dos Estados, e do Distrito Federal e Territórios que lhes são reservados ${ }^{10}$; para os dois cidadãos membros do Conselho Nacional de Justiça ${ }^{11}$ e do Conselho Nacional do Ministério Público ${ }^{12}$, indicados um pela Câmara dos Deputados e outro pelo Senado Federal e; para os Ministros do Tribunal de Contas da União que, além da reputação ilibada, se requer ainda "idoneidade moral"13. Tudo isso somente no texto da Constituição Federal, sem levarmos em consideração a repetição usual nas respectivas Constituições Estaduais, dada a importância do paradigma.

A mensagem é clara: os elementos humanos que se desincumbem das funções públicas de alta relevância, especialmente, as judiciárias, estão naturalmente acomodados nas expectativas de comportamento que - embasados na estrutura - integram a operacionalidade da superestrutura jurídica. Trocando em miúdos, eles representam o sistema jurídico ${ }^{14}$.

A superestrutura jurídica é normativa, mas também é cis-heteronormativa euronorcêntrica e hegemônica. As incongruências verificadas com o sistema sofrem uma seleção total, antes que vivências alternativas possam ser aceitas. É dizer, a necessidade de mudança só ocasiona transformação nos comportamentos quando a solução já se encontra sedimentada pela superestrutura e faz parte de padrões estabelecidos.

Ora, partindo-se do pressuposto que qualquer comportamento diferente é rechaçado justamente pela diferença, só passando a ser aceito quando o sistema o legitima por meio do consenso majoritário: poderíamos

\footnotetext{
${ }^{6}$ Art. $101, \mathrm{CR} / 88$.

${ }^{7}$ Art. $104, \mathrm{CR} / 88$.

${ }^{8}$ Art. $111-\mathrm{A}, \mathrm{CR} / 88$.

${ }^{9}$ Art. $131-\mathrm{A}, \mathbb{S} 1^{\circ}, \mathrm{CR} / 88$.

${ }^{10}$ Art. $94, \mathrm{CR} / 88$.

${ }^{11}$ Art. 103-B, XIII, CR/88.

${ }^{12}$ Art. 130-A, VII, CR/88.

${ }^{13}$ Art. 73, II, CR/88

${ }^{14}$ Celso Antonio Pinheiro de Castro (1999, p. 281) vai além ao asseverar que "os agentes do direito positivo representam o sistema, integram-se funcionalmente nele e correspondem ao que o sistema deles espera, sem questioná-lo". (grifo nosso)
} 
investigar se residiria aí a ausência de representatividade transviada ocupando os cargos acima arrolados? $\mathrm{Ou}$ somente poderíamos considerar a ideia a partir dos últimos julgados em que se reconheceu alguns dos direitos desta mesma comunidade transviada? Seria possível o reconhecimento da reputação ilibada e da idoneidade moral de sujeitos não-hetero/cisnormados?

Reputação ilibada e idoneidade moral, são conceitos fluidos, de abstratos, relativos, mas usados e entendidos pelo senso-comum (moral social/positivada) como sendo pertencente àquela pessoa adequada à moral e aos bons costumes. Entendemos que esta moral social dentro de relações de colonialidade, na medida em que representa a ideia de cis-heteronormatividade euronorcêntrica hegemônica. Trata-se de reforçar valores sem questionar sua origem e, sobretudo, que tipo de relações de poder sua manutenção perpetua.

Nesse sentido, Carlos Santiago Nino, na obra Ética e Direitos Humanos, ao discorrer sobre o movimento filosófico chamado de construtivismo moral, apresenta a sua concepção metaética destinada a "justificar os princípios normativos subjacentes à visão liberal de sociedade" ${ }^{15}$. Ensina que a moralidade social ou positiva é engendrada pela práxis e produto de reflexões acerca da moralidade ideal. Sem o desiderato de ação e balizamento em consonância com uma moral ideal, não existiria moral social ou positiva. Senão, veja:

A moralidade positiva é relevante apenas para o raciocínio prático de uma pessoa 'prudente' que está preocupada com uma reação social aos seus atos. Uma pessoa 'moral', cujo raciocínio prático visa justificar ações, preocupa-se exclusivamente com os ditames de uma moralidade ideal. Paradoxalmente a moralidade positiva é gerada pelas ações e atitudes da pessoa moral, mais do que da pessoa prudente. Uma moralidade social só sobreviverá na medida em que houver uma certa convergência nos juízos morais críticos das pessoas. Por isso, é equivocado isolar moralidade ideal da moralidade positiva (2011, p. 93).

Todavia é possível asseverar que o discrímen entre os juízos da moralidade ideal e da moralidade positiva consiste na validade das primeiras e na aceitação social das últimas. Obviamente que ao identificarmos a moralidade praticada por sociedades diversas é necessário fazer o que Nino entende por "ajustes mútuos com um sistema moral ideal", explicamos, para o autor causaria estranheza um sistema moral ideal que não guardasse correspondência comum com concepções morais aceitas em diferentes tempos e lugares, inobstante a validade de seus juízos.

A moral e a lei estão presentes em quase todas as sociedades, muitas vezes conversam, outras vezes não tem contato, mas o que é cediço para muitos, inclusive para Nino, é que "tanto a moralidade quanto a lei executam função social de superar certas dificuldades da vida humana em sociedade" (2011, p. 95). E tal se dá na exata tendência de as pessoas entrarem em conflitos e de sua tendência a cooperar.

A lei atua na redução de conflitos e favorece a cooperação social fazendo uso da autoridade e da coerção, todavia para Nino nenhum sistema legal pode se pautar unicamente no medo ou no interesse próprio, é mister

\footnotetext{
152011 , p. 92.
} 
que o funcionários judiciais e a população sejam convictos de que as regras do sistema são moralmente justificadas. A moralidade então supre uma incapacidade legal de adesão de condutas. A lei, pois, lança mão da condenação moral para a consecução dos seus fins. Assim, a moral impõe sanções informais para aqueles que a transgridem, tidas por Nino como reações sociais não organizadas, tais como, ostracismo, tratamento vexatório e expressões de repúdio.

Todavia, a reação social se baseia numa razão moral que não pertence ao agente, mas apenas se atribui através da crença de que deveria ser o móvel. Mas tal não ocorre apenas a fim de gerar razões prudenciais para elidir determinado comportamento, mas conduzir as pessoas a adotar razões morais em favor de certas condutas, de modo que, tais razões morais prevaleçam sobre razões dissidentes.

A prática social sistemática para convergência de comportamentos baseadas na coincidência de convicções de juízos morais é o que se chama de discurso moral. Para Nino (2011, p. 102) o objetivo do discurso moral é a "convergência em ações e atitudes por meio da livre aceitação por parte dos indivíduos de princípios gerais para guiar suas próprias condutas e suas atitudes em relação às ações de outros". Esta é a tinta principal do discurso moral e é o que o distingue de outras instituições, tais como a lei e a religião, por exemplo, que cumprem a mesmas funções sociais. O consenso é a única via possível da moral.

Uma vez abordada a teoria do moralismo construtivista através da perspectiva de Nino e apresentada a problemática aplicação dos conceitos abertos de reputação ilibada e idoneidade moral quando da seleção de pessoas aptas a desempenhar as mais relevantes funções da República, especialmente quando levamos em consideração as vivências da comunidade transviada, passemos então a tecer considerações sobre a cisheteronormatividade eurocêntrica hegemônica como um produto do colonialismo.

\section{SUBVERSÃO DECOLONIAL}

A heteronormatividade é lida, sob a ótica moderna e colonial como naturalizada e "normal", daí a construção histórica do sistema ideológico heterossexista e de processos de heteronormatização compulsória. Corolário disso é a efetivação de privilégios sociais para quem performatiza as regras (legais e morais, inclusive) heterossexuais e exclui os diferentes. Além disso, a cis-heteronormatividade é a ordem sexual do presente (Miskolci, 2012), fundada nesse modelo heterossexual, cis, binário, familiar (conforme a lógica cristã) e reprodutivo. Modelo estritamente relacionado ao dominante ${ }^{16}$, ao hegemônico e ao euronorcêntrico ${ }^{17}$.

\footnotetext{
${ }^{16}$ Ao trabalhar com a produção da heterossexualidade, Berenice Bento (2017, p. 199) anota que a mesma não tem relação com as práticas privadas, mas com poder. Para a autora a "produção de uma pessoa heterossexual é um projeto que deve contar com o apoio absoluto de todas as instituições: a família, a escola, e, claro, os representantes do Estado".
} 
A cis-heteronormatividade jurídica está afeita a criação e a manutenção de práticas tendentes a normalizar os corpos e as populações segundo as regras (legais e morais) supramencionadas. Araújo (2018), por exemplo, explica que ela atua ao excluir (incluindo) "todo conjunto heterogêneo de corpos não conformados pelas determinações da regra fazendo com que direitos, cuja marca é a universalidade, não lhe sejam assim garantidos por sua condição de não-heterossexual". E, não só se espraia, mas, cria um gradiente de normalidade onde os corpos passam a ser dispostos a partir de níveis de transgressão, e tal escalonamento permite a fruição seletiva de direitos na medida em que são absorvidos, ainda que parcialmente, pela cis-heteronormatividade.

A modernidade colonial apresenta a dicotomia hierárquica entre pessoa e não-pessoa como sua pedra angular. Segundo Lugones (2014) foi a partir da colonização das Américas e Caribe que o mundo experimentou esta distinção hierárquica dual e impositiva sobre os colonizados, acompanhada por outras dicotomias incluídas aí aquela que se dá entre homens e mulheres. Ocorre que apenas homens e mulheres eram consideradas pessoas, sendo esse padrão o mais significativo símbolo civilizatório colonial. Os nativos americanos, os africanos e os que apresentavam comportamento afetivo e sexual que destoasse do sistema cartesiano civilizador eram considerados não-pessoas, eram classificados como espécies animalescas, incontrolavelmente sexuais, verdadeiros selvagens. $\mathrm{O}$ homem (cis) branco, heterossexual, europeu, cristão, burguês, colonial moderno habitou a centralidade da vida pública e administrativa. Era o único dotado de razão e capaz de fazer juízos. As mulheres europeias burguesas eram lidas apenas como alguém que reproduzia a raça e capital, através de sua brancura, indiferença, castidade e destinação doméstica.

A contemporaneidade já informa que o gênero é construído ${ }^{18}$. Todavia, no passado gênero era sinônimo de sexo e a perspectiva colonial fazia a distinção de gênero especialmente quando da subalternização dos colonizados. Esta ferramenta normativa deu salvo conduto para atrocidades sexuais, controle de reprodução e terror. A missão civilizatória jogava os colonizados contra si próprios, fazendo uso do cristianismo para satanizar pessoas e condutas. Esse instrumento normativo apagou etnias, vivências, costumes e saberes, ramificando-se para todas as relações sociais e de poder, engendrando a desumanização constitutiva da colonialidade do ser.

A colonialidade dos gêneros e das sexualidades ainda está fortemente presente e arraigada nas relações

\footnotetext{
${ }^{17}$ Richard Miskolci (2012, p. 47) informa que o sistema educacional e a produção de conhecimento, inclusive o científico, ainda é feito através de uma perspectiva heterossexista. Já que "quando algo se apresenta como 'científico', deve-se desconfiar que foi feito em uma perspectiva masculina, branca, ocidental, cristã e heterossexual [...]. Na esfera da sexualidade e do desejo, a maior parte do que reconhecido socialmente como discurso autorizado a falar é produzido dentro de uma epistemologia dominante, criada sobre esta suposta 'cientificidade', que pouco difere de um compromisso com a ordem e poder".

18 Segundo Butler (2004) a performance de gênero é uma construção, os transgêneros são as pessoas que se identificam ou vivem de acordo com as normas sociais de outro gênero, mas que podem ou não ser submetidas a tratamentos hormonais ou cirurgias de redesignação sexual. O conceito pode também ser utilizado de forma mais ampla para designar pessoas que transitam no gênero, independente de modificação corporal realizada e até desejada, sendo incluso em tal conceito as identidades de transexuais,
} 
de poder contemporâneas. Daí porque é necessário repensar as vivências a partir da "diferença colonial", a despeito da complexidade que possa parecer é possível pensar num recomeço pautado na resistência. Para Lugones (2014) esta resistência "é a tensão entre a sujeitificação (a formação/informação do sujeito) e a subjetividade ativa, aquela noção mínima de agenciamento necessária para que a relação opressão/resistência seja uma relação ativa", podendo ser lida também como a moral social/positivada e moral crítica/ideal em diálogo e enfrentamento, ora adaptativa, ora criativamente opositiva a fim de um novo paradigma liberal.

Descolonizar as sexualidades transviadas é premente. É revelar uma crítica da subalternização de vivências sexuais racializadas, coloniais, capitalista objetivando uma alteração dos esquemas sociais. Inobstante isso, deve ser capaz de dialogar com os atores sociais da lógica da opressão, tem que estar de acordo com as subjetividades e intersubjetividades que parcialmente constroem e são construídas pelo sistema, deve necessariamente aprender e incluir.

Esta subversão decolonial propõe a partir da dissidência criar situações transcendentes através de uma perspectiva de subalternidade, de descolonização e, portanto, a redefinir um novo campo epistemológico onde o pensamento de fronteira é exercido. Com efeito a colonialidade permeou todos os aspectos da vida através da circulação do poder, nos corpos, do trabalho, da lei, da tributação, da propriedade e da expropriação de bens, a lógica colonial e energia foi sentida por variadas pessoas cujos corpos não se relacionam com a natureza seguindo a lógica do capital. Não seguem a lógica do poder, não porque subversivos, mas porque autênticos.

Essas ( $r$ )existências verdadeiramente legítimas vivem fragmentadas numa realidade dissociante, habitam na diferença colonial, subalternizadas de si mesmas, porém não resistem isoladas, são um subsistema tensionado comprometido com a ruptura. Aqui, no ponto de inflexão, desponta a nova forma de enxergar a lógica da diferença colonial, a partir do ponto de vista do oprimido, da diversidade e no consenso.

Dito isto, e expostas as escaras da colonização ainda presentes, é imperioso o abandono de padrões exigidos, inclusive, pela norma constitucional vigente, porque produto da contraditória e opressora cultura hegemônica. É fundamental que haja o reconhecimento dessas contradições e das consequentes violências sistemáticas contra direitos humanos assegurados. É o que trataremos a seguir.

\section{PRINCÍPIOS LIBERAIS SUBJACENTES AOS DIREITOS HUMANOS}

Numa sociedade que se pretende liberal como a brasileira, uma vez previstas na Constituição tanto o requisito de reputação ilibada como o de idoneidade moral, fulcrados no padrão de moralidade colonial

travestis, não-binários e drag queens. Aqui, como já explicitamos acima, usamos o termo guarda-chuva "transviados" para todos aqueles que não performam dentro da cisheteronormatividade. 
hegemônico e normalizado, traduz afronta aos princípios liberais subjacentes aos Direitos Humanos, os quais, na perspectiva de Carlos Santiago Nino, são os princípios: a) da autonomia pessoal; b) princípio da inviolabilidade da pessoa e; c) princípio da dignidade da pessoa humana, pois a escolha através de uma moral positivada do perfil de profissional adequado para as carreiras jurídicas favorece alguns e exclui e nega a própria humanidade de muitos outros dissidentes, causando uma grande frustração de perspectivas de planos de vidas e fortalecendo estereótipos. Partindo desse pressuposto discutiremos a seguir tais princípios, sugerindo uma conexão com os pressupostos da prática do discurso moral, com o objetivo de refinamento do equilíbrio entre a visão esclarecida do baldrame do discurso moral e da elaboração mais exata dos princípios que guarnecem nossas instituições morais.

Os direitos individuais fundamentais são uma combinação de um conjunto de princípios que constituem o baldrame de uma concepção liberal de sociedade (Nino, 2011, p. 173). Vamos tratar então como relação entre a imposição legal da moralidade positiva e o liberalismo na perspectiva desse autor.

Para ele, o debate acerca do tema parte da controvérsia sobre se a imoralidade de um ato constitui em si mesma a razão para que a lei atue. Nino entende que onde há um consenso o Estado pode, desde que justificadamente, estabelecer os princípios de uma moralidade pública ou intersubjetiva, que analisa as condutas em conformidade com suas consequências sobre os interesses de outros. Inobstante, poderia o Estado impor, através de sanções ou outros incentivos para determinado comportamento, os padrões de moralidade pessoal ou autorreferente, que, por sua vez, analisa as condutas pela sua consequência sobre o caráter moral sobre a valia da vida do próprio agente que as realiza.

O princípio da autonomia da pessoa, segundo Nino, "estabelece o valor da livre adoção individual de ideais de excelência humana e de planos de vida baseados nele" (2011, p. 177). Partindo desse pressuposto, nem o Estado nem indivíduos privados têm o poder de intervir na adesão e exercício de tais ideais e planos, circunscrevendo-se ao projeto das instituições que viabilizam a realização individual dos mesmos de modo a elidir interferências mútuas.

A concepção antagônica ao princípio da autonomia da pessoa é conhecida como perfeccionismo. Esta concepção parte da presunção de que o que é bom para os indivíduos não depende de suas preferências ou desejos, o Estado pode fomentar, inclusive lançando mão da força coercitiva, os ideais de virtude, planos de vida ou interesses que são "objetivamente melhores".

Nino fundamenta seu pensamento na ideia de que o princípio da autonomia da pessoa é uma norma válida considerada em si mesma ${ }^{19}$. Ademais, tanto o princípio da autonomia da pessoa como os princípios que

\footnotetext{
${ }^{19}$ A visão liberal, diferentemente da visão perfeccionista, não necessita posicionar-se quanto a validade desses ideais pessoais quando discute princípios de organização social, já que esses princípios não dependem dessa validade (NINO, 2011, p.181).
} 
governam sua atribuição são bastantes ricos para guarnecer a "organização social de todo um sistema normativo".

Decerto há um desalinho quando se pressupõe que a autonomia constitui uma propriedade de apenas alguns planos de vida, diante da possibilidade de seleção dentre uma ampla variedade, tantos quanto imagináveis puderem ser os de planos de vida. Tal visão enseja uma percepção equivocada de que, a despeito do valor da autonomia, alguns planos de vida são melhores que outros (ou que podem ser reprováveis sem serem danosos) e que isto é relevante para a ação do Estado. Outrossim, não fica suficientemente claro que as medidas não coercitivas possíveis de serem adotadas pelo Estado e que fomentam ou desencorajam ideais de vida não são capazes de cercear a autonomia das pessoas.

Ao contrário disso, o que se observa é que tais pessoas deixam de formular planos de vida conforme sua vontade autônoma para fazê-lo somente em relação àquilo que a sociedade considera possível diante das suas particularidades enquanto pessoa, isto é, a sociedade cria nichos sociais e define que características cada pessoa precisa ter para ocupar cada um deles.

O princípio da autonomia pessoal possui dois aspectos: a) avaliação positiva da autonomia individual na escolha e realização de concepções de bem e de planos de vida baseados nelas; b) a proibição do Estado e também de particulares de interferir no exercício dessa autonomia.

O primeiro aspecto está umbilicalmente ligado à característica principal do discurso moral, assim como já discutido no tópico 1, ela não atua através de coação, corrompimento ou disciplina, mas mediante consenso. Segundo Nino, "o que importa é a participação sincera na prática implica conferir valor à livre adoção de princípios morais" (2001, p.184). É desejável que as pessoas sujeitem a sua conduta apenas pela livre adesão de princípios que julguem válidos após exauriente meditação e providência. O desiderato imediato do discurso moral não é a adesão a princípios morais quaisquer, não importando quão abjetos sejam, mas a livre adesão a princípios morais válidos. Assim toda problemática aqui situa-se no terreno da validade. Senão, vejamos:

Se não há possibilidade de defender, no contexto do discurso moral, um princípio que nega o valor da autonomia moral, isso implica que esse valor é inerente à estrutura do discurso moral. Por conseguinte, a autonomia moral, que se manifesta na escolha de princípios morais em questão, as ações que são determinadas pela livre adoção de tais princípios morais para guiar a ação moral possui um valor moral prima facie. Esse valor prima facie da autonomia moral se transmite naturalmente às ações que são determinadas pela livre adoção dos princípios morais que as prescrevem. Qualquer que seja a validade dos princípios morais que as prescrevem. Qualquer que seja a validade dos princípios morais em questão, as ações determinadas pela adoção de tais princípios têm algum valor prima facie. Isso está refletido no que atualmente é chamado de autenticidade (NINO, 2011, p. 188).

Todavia, esse valor é apenas prima facie e pode ser anulado pelo desvalor de outros aspectos da conduta, de tal modo que compreensão última pode ser de que a suposta conduta, depois de uma avaliação geral, seria abominável. Especial e, talvez, exclusivamente quando a ação autônoma causa dano à autonomia de outrem.

Como dito, o segundo aspecto da autonomia pessoal é a vedação ao Estado e particulares de ingerência 
na seleção e exercício de ideais e concepções de vida boa pertencentes à moralidade autorreferente.

Interessante perceber que o princípio da autonomia da pessoa deve ser encarado de forma objetiva, é dizer prescinde das preferências individuais o que nos leva a acreditar que o valor dos bens úteis para preservação e expansão da autonomia pessoal quando da escolha dos planos de vida também é objetivo.

O dilema que se segue é saber se dentro de um esquema valorativo qual articulação deve ser a mais adequada: a maximização da satisfação das preferências ou dos planos de vida que as pessoas eventualmente aderem ou a maximização da capacidade de escolha de planos de vida ou preferências?

Nino assevera que o pensamento liberal contemporâneo elege apoiar o valor da capacidade de optar por diversos planos de vida a apoiar o valor de satisfazer as preferências já adotadas (2011, p. 192). Sustenta o autor que, sob uma concepção liberal de sociedade, as pessoas são conscienciosas pela escolha de planos de vida e pela adoção de preferências e que tais pessoas não podem ser vitimadas pelas suas próprias ações ou mesmo perceberem compensação estatal ou de outrem como se fossem portadores de necessidades especiais.

Todavia, ainda que a elaboração do princípio ora analisado nos permite acessar direitos individuais básicos, que consistem nos bens ou interesses que esses direitos protegem. E esses bens são fundamentais para a escolha e realização de planos de vida pelas pessoas.

O principal dele é a liberdade de realizar qualquer coisa que não cause dano a outrem. Outro bem indispensável é a vida biológica consciente, tanto para concretizar a maioria dos projetos pessoais, aí incluídas a possibilidade de pôr em perigo ou renunciar a própria vida. Mesmo que a diminuição voluntária da probabilidade de escolher planos de vida, ela pode constituir um aspecto essencial de um plano de vida que o indivíduo adotou com tal devoção que outras alternativas perderam o sentido para ele (Nino, 201 1, p.193).

O mesmo raciocínio aplica-se à integridade física e psíquica, não estar sujeito às agruras da dor, de desconfortos físicos, de depressão, de deformidades, noutro giro gozar plenamente de boa saúde física e mental, é uma condição que por si só amplia a capacidade de escolher e realizar planos de vida. Assim como contar com recursos que expandem tal desempenho.

O pleno desenvolvimento das faculdades mentais através de uma educação liberal que proporcione disseminar criticamente os padrões de moralidade intersubjetiva guarnece instrumentos para que a pessoa possa escolher seu próprio projeto de vida de modo cônscio, livre e sem imposição de dogmas.

A ampla liberdade de expressão deve ser defendida justamente porque baseada na norma básica do discurso moral, que por sua vez dá suporte ao princípio da autonomia moral do qual é fruto o princípio da autonomia pessoal.

A auto-realização de alguém só é possível uma vez exercitada satisfatoriamente as diversas modalidades da vida afetiva, sexual e familiar, assim o princípio da autonomia da pessoa é pilar para a mais ampla liberdade para 
que o indivíduo desenvolva sua vida privada e relacionamentos íntimos como bem lhe aprouver.

Para fruição desses bens supramencionados é necessário o acesso à estabilidade financeira. O trabalho é o meio que a possibilita através do dispêndio de energia e tempo tal desiderato. Mas essa é uma perspectiva dual, na medida em que ao ser um instrumento da auto-realização pode limitá-la quando indisponibiliza a atenção necessária para outros aspectos dessa mesma auto-realização, assim o lazer e o ócio são igualmente importantes e carentes de proteção. Por último, ressaltamos que a segurança pessoal deve ser protegida em face de qualquer vilipêndio a esses bens por ações arbitrárias.

Todos esses bens analisados agregam ao princípio da autonomia da vontade uma ideia de gozo que Nino chama de princípio hedonista vez que fundados no prazer e na ausência de dor, aos quais lhes são atribuídos um valor prima facie (2011, p. 195).

Os princípios da autonomia da vontade e hedonista são pois agregadores, conferem relevância a estado de coisas, à capacidade de escolher planos de vida ou à presença de prazer e à ausência de dor. Para o autor quanto mais esses valores forem concretizados melhor será o mundo.

\section{O PRINCÍPIO DA INVIOLABILIDADE DA PESSOA}

A privação daquilo que o princípio da autonomia pessoal e o princípio hedonista anunciam como bens constitui uma violência. O princípio da inviolabilidade da pessoa, pois, pode ser conceituado como a vedação de imposição, sem consentimento, de sacrifícios que não resultem em benefício. Destarte, e também da conjugação com os princípios da autonomia da pessoa e do hedonismo, ninguém pode ser usado como mero "meio", é dizer, como instrumento para o benefício de outra pessoa em detrimento de si próprio.

Segundo Nino, fundamentado na perspectiva kantiana, quando alguém persegue a perfeição, não deve buscar a perfeição nas condutas alheias, mas engendrar esforços para alcançar seus fins pessoais, trocando em miúdos, deve buscar o que entende por felicidade. É claro que quando se olha a sociedade como um superorganismo o enfrentamento da distribuição desses valores pode ser uma tarefa demasiada árdua, porque o individualismo é posto em rota de colisão com o coletivismo. ${ }^{20}$

Esse contraste de interesses se resolve a partir de uma atitude imparcial própria da moralidade. Para Nino a formulação do ponto de vista moral implicaria que sua base normativa deveria ser composta exclusivamente do

\footnotetext{
20 "O coletivismo não só nos confronta com um problema referente à relevância da distribuição, como faz o utilitarismo, mas com um problema evidentemente mais profundo referente a quem são os detentores dos interesses que deverão ser satisfeitos tanto no modo agregado quanto no modo distributivo. De acordo com ele, há entidades coletivas que possuem interesses que não são redutíveis aos indivíduos (como sustenta o utilitarismo) e que deveriam ser satisfeitos até mesmo a custa destes últimos. Por
} 
princípio da autonomia pessoal e do princípio hedonista, pondo-se ao largo qualquer intenção de reduzi-los através do princípio da inviolabilidade da pessoa (2011, p. 209).

Essa forma de raciocínio consiste em colocar-se na situação de cada uma das pessoas concernidas, num exercício contínuo de alteridade. E é assim por ser necessária uma generalização da inquietude impessoal com nossos próprios interesses, tudo a fim de tornar nossas diferentes ações em convergentes. Todavia, a convergência é garantida em alguns pontos simplesmente porque alguns interesses são protegidos pelos direitos que não podem ser invalidados contra a vontade do detentor de tais interesses. Assim, obtempera o autor:

Essa é a conclusão que parece decorrer do raciocínio moral que contempla separadamente os pontos de vista de todas as pessoas concernidas, sem confundi-las dentro de uma visão global; e, sendo essa a estrutura do discurso moral, certos possuem um papel insubstituível num sistema moral válido. A função dos direitos em questão consiste em 'entrincheirar' certos interesses de indivíduos, de tal modo que não possam ser deixados de lado, contra a vontade destes, em favor de interesses considerados mais importantes - seja intrinsecamente, seja por sua quantidade - pelos demais indivíduos (NINO, 2011, p. 213).

É um equívoco afirmar que o reconhecimento dos direitos fundamentais básicos pode ser vilipendiado pela necessidade de garantir o bem comum. Do contrário, é um meio preventivo que garante aos indivíduos que não sejam cerceados de seus bens a fim de favorecer outros indivíduos, a sociedade como um todo, ou um ente supra-individual. Relega-se, pois, uma visão coletivista que protesta que organismos supra-individuais gozam de autonomia. O bem comum é equivalente ao bem-estar daqueles que compõem a sociedade individualmente considerados presentes e futuros, vez que o bem comum é cumulativo e não individualizado.

O reconhecimento de tais direitos a partir do princípio da inviolabilidade da pessoa tem como consequência não apenas a restringir a persecução dos desideratos coletivos no âmbito majoritário de tomada de decisão próprios da democracia.

Essa limitação do bem comum pelos direitos individuais básicos não implica necessariamente na desqualificação da tomada de decisão majoritariamente democrática. $\mathrm{O}$ sistema pode se valer da esfera não coberta por certos direitos, uma esfera cuja latitude dependeria dos propósitos desses direitos. Para superar indeterminações morais pode-se, inclusive, recorrer para procedimentos democráticos.

Ocorre que mesmo nesses casos, se considerarmos que a Democracia pode ser moralmente justificada, baseada em certos direitos ou com base nas mesmas razões que dão suporte a esses direitos, o reconhecimento dos direitos não depende de uma decisão majoritária aplicação desses direitos, mas também pode ter o condão de balizar os resultados do procedimento.

Para Nino direitos humanos "são uma espécie de direitos morais e que eles proveem razões justificadoras para decisões tomadas por órgãos legais, quer tenham sido reconhecidas pela lei ou não" (2011, p. 215).

exemplo, para algumas dessas concepções, a nação é uma unidade moral básica e seus interesses podem prevalecer perante os de vol.11, no. 04, Rio de Janeiro, 2018.pp.3128-3147 
Inobstante é mister o reconhecimento a fim de ditar os direitos em xeque. Os direitos legais positivam os direitos morais e os impõem, tal pode ser controverso na praxis, tornando a decisão majoritária uma alternativa mais palpável. Todavia essa logicidade não muda a realidade dos direitos morais subjacentes, e ao fim é essa que deveria ser levada em consideração para motivar cada decisão.

O princípio da inviolabilidade da pessoa veda sacrifício ou dano a uma pessoa em desfavor de sua vontade fundado em qualquer benesse, mesmo que maximizada, para outras pessoas ou para a "totalidade supraindividual", dota a missão dos direitos cujo miolo é delimitado pelo princípio da autonomia pessoal e pelo princípio hedonista.

Conquanto estes últimos são agregadores que clarificam alguns estados de coisas como bons ou valioso, com o resultado de quanto mais deles realizarmos melhor será, debalde o compartilhamento pelos diferentes indivíduos, o princípio da inviolabilidade da pessoa é um princípio de distribuição que limita a satisfação dos outros princípios, caso a maior autonomia ou o maior prazer forem obtidos às custas da autonomia ou do prazer de alguns indivíduos.

Esse princípio fortalece os bens que são necessários para a autonomia ou o prazer, estabelecendo que ninguém pode ser privado de bens a fim de beneficiar terceiros ou ente supraindividual.

Todavia, é mister ocuparmo-nos, no próximo tópico, com outro princípio básico que preserva o princípio da inviolabilidade da pessoa e permite que possamos transpor o engessamento dos direitos caso fossem regidos unicamente pelos princípios antecedentes.

\section{O PRINCÍPIO DA DIGNIDADE DA PESSOA HUMANA}

Já foi tratado que as inclinações pessoais por determinados planos de vida não deveriam ser tidas por acidentais, mas como corolário de decisões pelas quais os indivíduos graças à sua autonomia moral e material para serem compromissadas. Já expomos que o que o princípio da inviolabilidade da pessoa rechaça é sacrifício, efetivo ou potencial, imposto a uma pessoa em função de outrem, é permitido quando o ônus é aquiescido pela pessoa que o suporta. O fato de a moralidade positivada/social depender da vontade das pessoas se contrapõe a um conjunto de ideias bem conhecidas, não obstante suas discrepâncias, convergem na desqualificação moral dessa vontade.

Segundo Nino, o fato de um indivíduo querer, decidir, ou consentir em algo nunca pode ser em si mesma uma razão que justifique uma outra ação ou outra decisão; tais considerações são sempre constituídas por

seus cidadãos, sem serem redutíveis aos interesses de outras pessoas." (NINO, 2011, p. 202) 
princípios morais ou prudenciais e são estes últimos que tornam certos atos de vontade moralmente relevantes (2011,p.217).

Com efeito o autor atribui um papel coadjuvante aos quereres e juízos humanos, fundamentado na perspectiva de que estas são revelações superficiais de fatos que possuem significado moral, como o pertencimento a determinada classe social, suas tradições culturais, sua ambiência social, além de tendências psicológicas, processos biológicos ou manipulação propagandística. Se assim não fosse, o aspecto volitivo poderia ser comparado a uma espécie de determinismo psicológico, físico ou até mesmo social, levando-nos a crer que a pessoa humana não teria controle sobre tais aspectos. Isso significaria que os indivíduos não têm liberdade para agir como o fazem, não podendo ser thes atribuídas qualquer responsabilidade.

Nino, à luz dos ensinamentos de Ted Honderich, aduz que para que uma ação seja voluntária é fundamental não apenas que o agente detenha a "liberdade de espontaneidade" (que ocorre quando a ação é causada pela vontade), mas também que ele desfrute da "liberdade da indiferença" (que implica que poderia ter querido de outro modo) (Nino, 2011, p. 221). Essa posição parece estar correta porque adequada com o fato de que, quando a vontade do agente deriva de fatores externos que a explicam de um modo simples, como ameaças sérias de terceiros consideramos a ação não livre e excluímos a responsabilidade do agente.

A responsabilidade moral por uma conduta constitui um tipo de juízo sobre o valor moral das ações (Nino, 2011, p. 222). Pode-se avaliá-los através de seus efeitos sobre os direitos ou bem-estar das pessoas (moralidade intersubjetiva), que leva em consideração o desiderato de revelar a ação não considerando a prejudicialidade a certos interesses, mas infirmando que não foi moralmente recusável porque satisfez outros pressupostos morais. Pode-se também negar a conexão entre a conduta e seus possíveis efeitos causais. Esta avaliação é objetiva, vez que não considera ações mentais, móveis, quereres, crenças, etc.

Nino entende que os juízos que atribuem responsabilidade moral são de outra tipologia; eles asseveram a culpabilidade do agente pelo cometimento de uma ação má. Da mesma forma como quando da infração legal o agente está submetido a uma sanção discriminada na lei, a atribuição de responsabilidade moral traduz a ideia que o agente está sujeito a uma sanção de acordo com as regras morais.

Os juízos que se opõem aos que implicam responsabilidade moral elencam uma lista de desculpas ${ }^{21}$ que objetivam neutralizar a censura moral imputável ao agente, porque atingem o elo entre a intenção de cometer um mau ato e a inclinação perversa do indivíduo. Nino, fundamentado na doutrina de Glover, afirma que usualmente relacionamos as pessoas com suas condutas (Nino, 2011, p. 226). E isto é impreciso pois ao fim a identificação se dá com o caráter moral das pessoas, do qual as ações e intenções são apenas um fenômeno. Ipso facto, tais juízos

\footnotetext{
${ }^{21}$ Tais desculpas vão desde erro ou ignorância, coerção irresistível por terceiros, reflexos inevitáveis ou até mesmo, em casos de omissões, a possibilidade de o agente não ter a capacidade específica ou que não possuía recursos externos
} 
habitam a moralidade autorreferente/pessoal e não a social/positivada.

A lei, por seu caráter abstrato, não pode extrair significado de enunciados meramente factuais, a não ser que se tratem de "fatos morais", entendidos como aqueles relevantes para o significado de termos normativos ou avaliativos. Mas essa abstração normativa, tomada como consentimento ou decisão não pode ser considerada na justificação de distribuição de ônus ou outros arranjos, somente seria considerada válida essa construção se tal ilação aceitar a como premissa superior complementar algum princípio normativo mais básico e mais geral. Caso isto acontecesse estaríamos diante do que Nino chamou de determinismo normativo (Nino, 2011, p. 231).

Para tal autor, esse determinismo contrasta com o que entendemos ser o princípio da dignidade da pessoa, isto porque a concepção que fazemos de nós mesmos quando consideramos os quereres e juízos não se faz presente em outras características como cor da pele, etnia ou sexualidade, por exemplo. O princípio da dignidade preceitua que as pessoas devem ser tratadas de acordo com seus juízos, quereres, e externalizações de assentimento, e que estas podem ser tidas como precedentes de deveres e responsabilidades, soa tão elementar que quase esvazia o sentido de ser uma diretiva de moralidade positiva/social.

Entrementes, sua extrema relevância como diretiva de moralidade social reside pela falta de outra. Com efeito, quando adotamos a dignidade da pessoa deixamos de adotar princípios ou diretivas morais que preceituam levar em consideração a cor da pele, a inteligência, o gênero, a sexualidade, a diretiva é equiparada um ingrediente fulcral na concepção liberal da sociedade.

Presume-se, pois, que os princípios que conferiram relevância a outras características não podem ser validados, desponta da admissão do princípio da dignidade da pessoa a invalidade de qualquer medida que promova o discrímen de pessoas, ao distribuir bens e recursos com base em aspectos que estão fora do alcance da vontade.

A nossa dignidade como pessoas é vilipendiada quando não apenas nossos juízos são aquilatados, e.g, a enfermidades, mas também quando estende-se a convicções e opiniões. Quando alguém concebe as suas opiniões e convicções e as de outros como objeto de debate e desconsidera as dos outros como no mesmo nível que as suas próprias convicções, tal qual quando a opinião que o conduz a adotar determinada conduta em relação a nós, sentimos que ele não está conferindo isonomia no trato e que nos é negada o status moral que distingue a ele e a todos nós de outras coisas que habitam o mundo.

\section{O FIM DA REPUTAÇÃO ILIBADA E DA IDONEIDADE MORAL}

Até aqui discorremos sobre vários aspectos filosóficos, sociais e jurídicos que, ao fim, nos ajudam a compreender que simples permanência em textos normativos dos termos reputação ilibada e idoneidade moral 
violentam fortemente o que entendemos como dignidade humana.

Primeiro porque são normas moralmente vazias; segundo porque excluem estilos de vida numa sociedade em que não deve haver discriminação, posto que se afirma como Estado Democrático de Direito; terceiro porque oprime os profissionais do Direito a terem que padronizar comportamentos que não necessariamente são os desejados para si; e, por último, interferem diretamente na escolha de planos de vida.

Ora, se o conteúdo dos termos é esvaziado em decorrência dos princípios liberais subjacentes aos Direitos Humanos, vale dizer, cláusulas pétreas constitucionais, vejam só que contradição: o sistema de justiça deve distribuir equidade representando a sociedade. Como representar uma sociedade extremamente fraturada e estratificada como a brasileira impondo um padrão de comportamento que repousa em berço esplêndido nos ideais morais europeus da época da colonização?

É interessante observar que muito pouco se fala nisso, nem mesmo os tribunais enfrentam o tema, do contrário, reforçam sempre a ideia de uma conduta idealizada e irreal, desdes as aulas nas faculdades, até nas salas de audiências, num contrassenso torturante assim como exige-se o uso de vestes "talares" num país de clima tropical como o nosso. Com toda certeza não será o modo como vestimos ou como nos relacionamos afetivamente que serão determinantes para a atuação profissional. Esta opressão vai além, não apenas nos profissionais do Direito a suportam, mas bem das vezes seus clientes que não podem adentrar os Palácios da Justiça vestindo alpargatas, por exemplo.

O ideal cis-heteronormativo conjugado com a moralidade positivada influenciam diretamente na autonomia da vontade, violando a inviolabilidade da pessoa e a dignidade humana, e isso ocorre porque a ideia da moralidade idônea e da reputação imaculada opera, através do Direito, uma forma de repressão muito própria que faz com que pessoas, mesmo que desejem traçar planos de vida em torno de profissões jurídicas deixam de fazê-lo, porque acreditam que se o assim fizerem não serão exitosas.

Outras muitas que escolhem seguir passam por um processo intenso de enquadramento onde o modo de falar, o corte de cabelo e as vestes influenciam no acesso ao sistema. Outros muitos, mesmo que já devidamente "enquadrados" sofrem discriminações e até retardamento em progressões de carreira. Nenhum representante abertamente LGBT, por exemplo, alcançou esses mais altos cargos na República no Brasil.

De um modo bem pragmático, o sentimento que fica é que as expressões reputação ilibada e idoneidade moral não querem dizer outra coisa se não que padrão o reconhecimento se limita ao cidadão homem, branco, heterossexual e cristão e que qualquer coisa fora disso não cumpre o requisito.

O problema é que o que assistimos no Brasil atualmente é o fortalecimento desses conceitos sem qualquer balizamento objetivo, o que a torna uma ferramenta perigosamente antidemocrática e que, por esse motivo, não se compatibiliza com o Estado Democrático de Direito. 


\section{CONCLUSÃO}

No colonialismo a primazia binária homem-mulher era agenda civilizatória, assim como todos os modos, usos e costumes. A normalização era a regra, e servia de discrímen entre os colonizadores e os colonizados. Num complexo sistema tecido numa trama imbricada de relações engendradas social, cultural e historicamente, fundamentados por estudos científicos, teológicos e políticos que impunham não só a heterossexualização compulsória, mas a racialização e o enquadramento social no padrão hegemônico eurocêntrico.

A formação do Brasil como Nação parte desse pressuposto, ocorre que mesmo com o fim do colonialismo ainda vivemos sob sua forte influência que perpassa as mais diversas relações sociais e de poder. A lógica colonial está presente em quase "tudo" na sociedade contemporânea brasileira, uma vez que as práticas institucionais vigentes são fundamentadas naqueles pressupostos morais, religiosos, científicos, acadêmicos, filosóficos, políticos, sociais, culturais e etc., fomentando o apagamento das características nativas, naturalmente sincréticas, do nosso povo, violando sistematicamente comunidades inteiras.

O Estado, por óbvio, também está fundamentado nestes mesmos parâmetros, especialmente no sistema de justiça, pois, para além de interpretar e aplicar o Direito, faz sindicância de aspectos morais flagrantemente discriminatórios e excludentes ao eleger padrões de condutas sociais e morais, sem critérios objetivamente delimitados, dissociados da realidade multifacetada e, bem das vezes, minoritária, em contradição com o rol garantista liberal individual inaugurado com a Constituição da República de 1988.

Essa discrepância produz um engessamento das estruturas administrativas e judiciárias, fazendo com que comunidades legitimamente interessadas na participação ativa na formação da vontade do Estado sejam completamente alijadas, porque não performatizam suas vivências dentro dos padrões hegemônicos. Os transviados seguem seu caminho marginalizados e não lhes são reconhecidos o acesso às mais relevantes funções da República.

Com efeito, a escolha através de paradigmas de uma moral positivada do perfil de profissional adequado para as carreiras jurídicas favorece alguns e exclui e nega a própria humanidade de muitos outros dissidentes, causando uma grande frustração de perspectivas de planos de vidas e fortalecendo estereótipos, engessando as superestruturas jurídicas.

Não só a exigência, mas a manutenção no texto constitucional e demais textos normativos da "reputação ilibada" e da "idoneidade moral", como dispositivos morais são esvaziados ao serem lidos em conformidade com os princípios liberais subjacentes, abordados por Nino (2011), especialmente os princípios da autonomia da pessoa, da inviolabilidade da pessoa e da dignidade da pessoa humana. Sendo, portanto, exigências moral e juridicamente inválidas. 


\title{
THE INVALIDITY OF ACQUITTED REPUTATION AND MORAL SUITABILITY: DECOLONIAL REFLECTIONS
}

\begin{abstract}
The purpose of this article is to discuss non-performatized experiences within the hegemonic heteronormativity in the absence of queer representatives in relevant public functions in the Brazilian Republic, particularly in the Judiciary Power For access to various positions of the Judiciary and other legal careers, in addition to notorious legal knowledge, the Brazilian constitutional norm, among other requirements, requires "unqualified reputation" and / or "moral suitability" on the part of the candidate - fluid concepts, of great abstraction, but used and understood by the common sense as belonging to that person framed in standardized moral standards. We understand this social morality as the fruit of a colonial process, reflecting processes of coloniality, since the notion of "morals and good customs" reinforces stereotypes of gender, family, corporality, behavior and morality normalized according to modern (and therefore, binary and Christian). Decolonial perspectives allow an exercise of critical reflection on the constitution and consolidation of both the notions of unblemished reputation and moral propriety. In the end, we demonstrate that "unblemished reputation" and "moral suitability" as constitutional moral devices are depleted by being read in accordance with the underlying liberal principles of Human Rights.
\end{abstract}

Keywords: Acquitted Reputation. Moral suitability. Interdisciplinarity. Decoloniality. Human rights.

\section{REFERÊNCIAS BIBLIOGRÁFICAS}

ADORNO, Theodor; HORKHEIMER, Max. Dialética do Esclarecimento. Rio de Janeiro: Jorge Zarhar, 1986.

ADORNO, Theodor. “Televisão e Formação”. Educação e Emancipação. Rio de janeiro, Paz e terra, 1995.

ARAÚJO, Dhyego Câmara de. Heteronormatividade jurídica e as identidades LGBTI sob suspeita. Rev. Direito Práx, Rio de Janeiro, v.9, n. 2, p. 640-662, June 2018.

BENTO. Berenice. Transviad@s: gênero, sexualidade e direitos humanos. Salvador: EDUFBA, 2017. 
A reinvenção do corpo: sexualidade e gênero na experiência transexual. Rio de Janeiro: 2006.

BUTLER, Judith. Undoing Gender. New York: Routledge. 2004.

BRAGATO, Fernanda. "Discursos Desumanizantes e Violação Seletiva de Direitos Humanos sob a Lógica da Colonialidade”. vol. 09, n. 04, Rio de Janeiro: Quaestio Iuris. 2016.p. 1806/1823.

CASTRO, Celso Antonio Pinheiro de. Sociologia do direito: fundamentos de sociologia geral aplicada ao direito - 6. ed. - São Paulo: Atlas, 1999.

HOUAISS, Antônio e VILLAR, Mauro de Salles. Dicionário Houaiss da Língua Portuguesa. Rio de Janeiro: Objetiva, 2001.

JUSTEN FILHO, Marçal. Curso de Direito Administrativo. São Paulo: Saraiva, 2005.

LUGONES, María. "Rumo a um feminismo decolonial”. Rev. Estud. Fem., Florianópolis, v. 22, n. 3, p. 935-952, Dec. 2014.

MISKOLCI. Richard. Teoria Queer: um aprendizado pelas diferenças. 2.ed. rev. e ampl. Belo Horizonte: Autêntica Editora: UFOP - Universidade Federal de Ouro Preto, 2012.

NINO, Carlos Santiago. Ética e Direitos Humanos. São Leopoldo: Unisinos, 2011.

Trabalho enviado em 29 de outubro de 2018

Aceito em 03 de novembro de 2018 